\title{
Relationship between insulin resistance and adipocytokines: the mediator role of adiposity in children
}

Caroline Brand, Adroaldo Cezar Araujo Gaya, Arieli Fernandes Dias, Cesar Agostinis-Sobrinho, Juliano Boufleur Farinha, Francesco Pinto Boeno, Jorge Mota, Alvaro Reischak de Oliveira \& Anelise Reis Gaya

To cite this article: Caroline Brand, Adroaldo Cezar Araujo Gaya, Arieli Fernandes Dias, Cesar Agostinis-Sobrinho, Juliano Boufleur Farinha, Francesco Pinto Boeno, Jorge Mota, Alvaro Reischak de Oliveira \& Anelise Reis Gaya (2020): Relationship between insulin resistance and adipocytokines: the mediator role of adiposity in children, Annals of Human Biology, DOI: 10.1080/03014460.2020.1740320

To link to this article: https://doi.org/10.1080/03014460.2020.1740320

Published online: 13 Apr 2020.

Submit your article to this journal

View related articles

View Crossmark data $\nearrow$ 


\title{
Relationship between insulin resistance and adipocytokines: the mediator role of adiposity in children
}

\author{
Caroline Brand $^{\mathrm{a}}$ (D) Adroaldo Cezar Araujo Gaya ${ }^{\mathrm{a}}$ (D), Arieli Fernandes Dias ${ }^{\mathrm{a}}$ (D) , Cesar Agostinis-Sobrinho $^{\mathrm{b}}$ (D), \\ Juliano Boufleur Farinha ${ }^{a}(\mathbb{D})$, Francesco Pinto Boeno ${ }^{a}\left(\mathbb{D}\right.$, Jorge Mota ${ }^{c}\left(\mathbb{D}\right.$, Alvaro Reischak de Oliveira $^{\mathrm{a}}$ (D) and \\ Anelise Reis Gaya ${ }^{a}$ iD

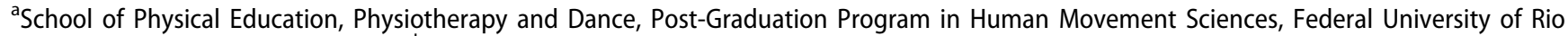 \\ Grande do Sul, Porto Alegre, Brazil; ${ }^{b}$ Faculty of Health Sciences, Klaipeda University, Klaipeda, Lithuania; ${ }^{C}$ Faculty of Sport, University of \\ Porto, Porto, Portugal
}

\begin{abstract}
Background: Leptin and adiponectin interact with each other in the modulation of obesity and insulin resistance (IR) and it is also important to consider the role of cardiorespiratory and muscular fitness in these relationships.

Aim: To analyse the relationship between IR with adipocytokines in children, and to test the mediation effect of \%BF (percentage of body fat) in the association of IR with leptin, adiponectin, and L/A ratio.

Subjects and methods: This cross-sectional study comprised a sample of 150 schoolchildren, aged 6-11 years, from school in Porto Alegre, Brazil. The following variables were evaluated: cardiorespiratory fitness (CRF), muscular fitness (MF), percentage of body fat (\%BF), and biochemical variables (leptin, adiponectin, glucose, and insulin).

Results: IR was associated with leptin and L/A ratio, after adjustments for age, sex, sexual maturation, and CRF. When adjusted for age, sex, sexual maturation, and MF, an association was found between IR with leptin and L/A ratio. Moreover, \%BF was a mediator in the association between IR and leptin, as well as IR and L/A ratio, explaining $54 \%$ and $57 \%$ of these associations, respectively.

Conclusion: Leptin and L/A ratio are positively associated with IR after adjustments. Also, \%BF is a mediator in the associations between IR and leptin and L/A ratio.
\end{abstract}

ARTICLE HISTORY

Received 16 December 2019

Revised 10 January 2020

Accepted 2 March 2020

\section{KEYWORDS}

Leptin; adiponectin; fatness; physical fitness; student

\section{Introduction}

Insulin resistance (IR) is considered as a major pathophysiological factor in the development and progression of type 2 diabetes mellitus; and it has been associated with low-grade inflammation and several metabolic complications (Friend et al. 2013; Esser et al. 2014). Moreover, studies have been suggesting that children with IR have a higher predisposition to future development of type 2 diabetes mellitus and cardiovascular disease (Medeiros et al. 2011; Skoczen et al. 2015). The mechanisms by which IR occurs are not completely understood, it is essentially characterised by the decreased capacity of insulin to act on target tissues (muscle, liver, and adipose tissue), leading to hyperglycaemia and increased chronic inflammatory process (Van Greevenbroek et al. 2013).

IR is also known to be associated with obesity in children and adolescents (Romualdo et al. 2014). Adipose tissue is currently known to secrete a large number of factors with diverse functions. These factors include proteins, termed adipocytokines, that act in an autocrine, paracrine, or endocrine fashion to control various metabolic functions (Pittas et al. 2004). Adipocytokines are adipose tissue-derived molecules, also associated with impaired vascular function, acute cardiovascular events, and obesity (Esser et al. 2014).

Adiponectin is an important adipocytokine and it is involved in improving lipid metabolism, regulating energy balance, inhibiting vascular inflammation, and increasing insulin sensitivity (Ghadge et al. 2018). Otherwise, leptin has key roles in the regulation of energy balance, body weight, metabolism, and endocrine function, presenting higher blood concentration in obesity (Allison and Myers 2014). Indeed, these adipocytokines act in different ways on subclinical inflammation, while leptin upregulates proinflammatory cytokines, adiponectin has anti-inflammatory properties (Yadav et al. 2013). More recently, it has been suggested that leptin and adiponectin interact with each other in the modulation of obesity and IR, thus the leptin/adiponectin ratio (L/A ratio) has been investigated as a possible predictor of metabolic disorders (López-Jaramillo et al. 2014).

Some studies in children and adolescents have shown associations of leptin, and adiponectin with IR, after adjustments for age, body mass index, sex, and pubertal stage (Huang et al. 2004; Aycan et al. 2005; Panagopoulou et al. 2008). However, previous studies have overlooked potential confounders, such as cardiorespiratory fitness (CRF) and muscular fitness (MF). Thus, we highlight that CRF and MF should 
also be considered, since both are important health indicators inversely associated with a proinflammation status in children and adolescents (Ruiz et al. 2009; Agostinis-Sobrinho et al. 2016; 2018; Agostinis-Sobrinho, Moreira, et al. 2017). Also, we intend to add new information regarding the relationship between $I R$ and adipocytokines, by determining quantitatively how much adiposity influences this association. We hypothesise that percentage of body fat (\%BF) is a mediator in the relationship between IR with leptin, adiponectin, and L/A ratio. Therefore, the purpose of the present study was twofold: to analyse the relationship between IR with adipocytokines in children; and to test the mediation effect of \%BF in the association of IR with leptin, adiponectin, and $\mathrm{L} / \mathrm{A}$ ratio.

\section{Subjects and methods}

\section{Study design}

This is a cross-sectional study, using a quantitative approach, developed in a public school from Porto Alegre, Brazil. This study is part of the "Sport and Health Project at School" (it is an intervention programme with physical activity and nutritional education, to promote physical fitness and cardiometabolic risk factors in children). The population of the study comprises 380 children in the first to fifth grade of elementary school. All parents of children were fully informed about the study goals, and those who agreed signed the consent form. Thus, the study was carried out with 150 schoolchildren (78 boys), aged 6-11 years. The exclusion criterion was did not attend the blood evaluation after three consecutive appointments. The Ethics and Research Committee of the Federal University of Rio Grande do Sul approved this study (2014997) according to the Helsinki Declaration.

The minimum number of subjects of the sample was calculated through the software G*Power version 3.1.9.2 (Düsseldorf, Germany). For sample calculation, an effect size $F$ of 0.15 (medium effect) was used, as well as a level of significance of .05 and statistical power of 0.95 . Linear regression models were used with approximately five predictors and a $5 \%$ increase to cover for possible losses and refusals. Based on these criteria, the minimum sample size was 143 children.

\section{Measures}

Physical fitness variables were measured at school by trained researchers. Nurses collected blood samples and physical education professionals measured \%BF at the laboratory of physiology of the Federal University of Rio Grande do Sul.

\section{Muscular fitness}

The described procedures of MF evaluation followed the "Projeto Esporte Brasil" (PROESP-Br) protocols (Gaya and Gaya 2016). Lower limb strength test was carried out with a measuring tape fixed on the floor. The starting line was signalled using a frame chalk at the zero point of the measuring tape. The student stood immediately behind the starting line, with feet parallel and knees semi-flexed. At the signal, the children jumped as far as possible with both feet together. Abdominal strength test was performed with the children in the supine position with knees flexed, arms crossed over the thorax, and ankles fixed to the floor by the evaluator. The children had to flex the trunk until he/she touched the thighs with the elbows, returning to the starting position, as many times as possible in one minute.

The results of the lower limb strength and abdominal strength test were transformed to standardised values ( $Z$ scores) by age and sex. Then the sum of $Z$-scores was performed to create the MF score.

\section{Cardiorespiratory fitness}

CRF was assessed using a running and walking test in six minutes (Bergmann et al. 2014), following the protocol of PROESP-Br (Gaya and Gaya 2016). Children were instructed to accomplish the greatest number of turns, running, or walking, in a sports court with the perimeter marked with cones and the floor with indications of metres. The measurement of the test was noted from the number of laps performed, plus the metres in the case of those who at the end of the time did not complete a lap, so after multiplying the number of laps by the perimeter of metres covered, the estimate of CRF was obtained and expressed in metres.

\section{Sexual maturation}

Sexual maturation was evaluated according Mirwald et al. (2002). Through this method it is possible to set the distance, in years, that the child is from peak height velocity. The following measures were considered: height, body mass, chronological age, length of lower limb, and height in the sitting position. These variables were used in a specific equation for sex.

\section{Blood sampling}

Venous blood samples were drawn by a specialised professional using disposable materials. Blood sampling was performed early in the morning following 10-12 $\mathrm{h}$ fasting. Blood samples were routinely centrifuged and then plasma and serum were aliquoted and frozen at $-80^{\circ} \mathrm{C}$ until analysis. Leptin and adiponectin levels were determined by enzymelinked immunosorbent assay (ELISA), following the specifications of the manufacturer (Abcam, Cambridge, UK). Thus, the leptin/adiponectin ratio was calculated. Glucose levels were determined using an automated analyser (Cobas C111, Roche Diagnostics, Basel, Switzerland). Insulin concentrations were determined by ELISA using commercial kits (DRG International, Springfield, USA). As an index of IR, HOMA-IR was calculated as the product of fasting glucose ( $\mathrm{mmol} / \mathrm{L}$ ) and insulin $(\mu \mathrm{lU} / \mathrm{mL}$ ) levels divided by 22.5 (Matthews et al. 1985). The result of HOMA-IR was transformed to standardised values ( $Z$-scores) by age and sex. 
Table 1. Participant characteristics.

\begin{tabular}{|c|c|c|c|c|}
\hline Characteristics & $n$ & $\begin{array}{c}\text { Total } \\
\text { Mean (SD) }\end{array}$ & $\begin{array}{c}\text { Boys } \\
\text { Mean (SD) }\end{array}$ & $\begin{array}{c}\text { Girls } \\
\text { Mean (SD) }\end{array}$ \\
\hline Age (years) & 150 & $8.63(1.49)$ & $8.53(1.50)$ & $8.72(1.50)$ \\
\hline Height (m) & 143 & $1.34(0.10)$ & $1.33(0.10)$ & $1.35(0.10)$ \\
\hline Weight (kg) & 142 & $34.05(10.95)$ & 32.62 (10.17) & $35.60(11.61)$ \\
\hline Sexual maturation & 138 & $-2.77(1.80)$ & $-3.95(1.04)$ & $-1.56(1.61)^{*}$ \\
\hline Body mass index $\left(\mathrm{kg} / \mathrm{m}^{2}\right)$ & 142 & $18.32(3.84)$ & $17.94(3.61)$ & $18.75(4.09)$ \\
\hline Cardiorespiratory fitness (m) & 145 & $751.16(130.27)$ & $785.33(136.21)$ & $712.47(112.10)^{*}$ \\
\hline Lower limb strength $(\mathrm{cm})$ & 145 & $110.08(23.74)$ & $117.29(23.59)$ & $104.04(22.04)^{*}$ \\
\hline Abdominal strength (rep) & 145 & $25.57(10.84)$ & $27.45(10.76)$ & $23.44(10.61)^{*}$ \\
\hline Muscular fitness & 145 & $-0.001(0.85)$ & $0.23(0.82)$ & $-0.24(0.82)$ \\
\hline Percentage of body fat (\%) & 118 & $33.52(8.55)$ & $31.50(8.54)$ & $36.17(7.72)^{*}$ \\
\hline Insulin (uU/mL) & 148 & $15.85(11.98)$ & $13.46(10.57)$ & $18.10(12.81)^{*}$ \\
\hline Glucose (mg/dL) & 149 & $89.35(9.10)$ & $88.33(7.52)$ & $90.43(10.62)$ \\
\hline Insulin resistance (HOMA-IR) & 148 & $3.50(2.10)$ & $2.97(2.37)$ & $3.99(2.71)^{*}$ \\
\hline Adiponectin ( $\mu \mathrm{g} / \mathrm{ml})$ & 150 & $10.92(6.49)$ & $12.07(6.97)$ & $9.54(5.65)^{*}$ \\
\hline Leptin (ng/mL) & 150 & $4.12(6.21)$ & $3.04(4.90)$ & $5.32(7.26)^{*}$ \\
\hline Leptin/adiponectin ratio & 150 & $1.25(4.84)$ & $0.72(2.25)$ & $1.85(6.61)$ \\
\hline
\end{tabular}

SD: standard deviation.

*Independent $t$-test for differences between boys and girls $(p<.05)$.

\section{Percentage body fat}

Percentage body fat was measured by dual-energy X-ray absorptiometry (DEXA) (Lunar Prodigy Primo, General Electric Healthcare; Madison, WI), by the same well-trained professionals. Children were positioned on the DEXA table in the supine position with the members properly separated from the trunk and had to remain in that position throughout the procedure. The children were lightly dressed.

\section{Statistical analysis}

All the statistical analyses were carried out using IBM SPSS 21 (SPSS, Inc., Chicago, Illinois, USA). The level of statistical significance was established as $p \leq .05$. All variables were checked for normality. Means and standard deviation were used to describe sample characteristics. Independent twotailed $T$-tests were used to examine the sex differences. The associations between IR with leptin, adiponectin, and L/A ratio were verified through linear regression, using different models: model 1 (crude model); model 2 (adjusted for age, sex, and sexual maturation), model 3 (adjusted for age, sex, sexual maturation, and CRF); and model 4 (adjusted for age, sex, sexual maturation, and MF).

To examine whether the associations between IR and leptin, adiponectin and $\mathrm{L} / \mathrm{A}$ ratio were mediated by $\% \mathrm{BF}$, linear regression models were fitted using the PROCESS macro for the Statistical Package for Social Sciences (SPSS) version 24.0 (IBM Corp, Armonk, NY, USA). The goal of this model was to investigate the total $(c)$ and direct effects $\left(a, b, c^{\prime}\right)$, reflected by the unstandardised regression coefficient and significance between the independent and dependent variables in each model. The model also investigated the indirect effect obtained from the product of coefficients $(a \times b)$, which indicates the change in the leptin, adiponectin or L/A ratio for every unit change in the IR that is mediated by the proposed mediator (i.e. \%BF). The PROCESS macro used bootstrapping methods recommended by Preacher and Hayes (2008) for testing mediation hypotheses, using a resampling procedure of 10,000 bootstrap samples. Point estimates and confidence intervals $(95 \%)$ were estimated for the indirect effect. The point estimate was considered significant when the confidence interval did not contain zero. Thus, the following criteria were assumed to establish mediation: (1) the independent variable (IR) is significantly related to the mediator (\%BF); (2) the independent variable (IR) is significantly related to the dependent variables (leptin, adiponectin, and $\mathrm{L} / \mathrm{A}$ ratio); (3) the mediator (\%BF) is significantly related to the dependent variable (leptin, adiponectin, and L/A ratio); and (4) the association between the independent and dependent variable is attenuated when the mediator is included in the regression model (Baron and Kenny 1986). The analyses were adjusted by age and sex.

\section{Results}

Table 1 presents the participants' descriptive characteristics. Girls showed higher levels of percentage of body fat, insulin, $I R$, and leptin than boys. While boys presented higher levels of CRF, lower limb strength, abdominal strength, and adiponectin than girls.

Table 2 shows the relationship between IR with leptin, adiponectin, and L/A ratio in children. Results indicate that IR is positively associated with leptin and L/A ratio after adjustments for sex, age, sexual maturation, CRF, and MF, and also for the unadjusted model. The highest correlation values were observed for the unadjusted model and adjusted for sex, age, and sexual maturation in both leptin and L/A ratio. Regarding adiponectin, there was no association found with IR.

The analysis of the mediation effect of \%BF in the association of IR with leptin (Figure 1) and L/A ratio (Figure 2) indicated that in the first regression equation $(a)$, the relationship between IR and \%BF was positive $(p=.01)$. In the second equation $(c), I R$ was also positively associated with leptin $(p<.001)$ and L/A ratio $(p<.001)$. The third equation $(b)$ showed a positive relationship between $\% \mathrm{BF}$ and leptin $(p<.001)$. Finally, in the fourth equation $\left(c^{\prime}\right)$, when IR and $\% \mathrm{BF}$ were included simultaneously in the model, \%BF was associated with leptin $(p<.001)$. For L/A ratio, the third equation $(b)$ showed a positive relationship between \%BF 
Table 2. Regression coefficients examining the association of insulin resistance with leptin, adiponectin, and leptin/adiponectin ratio.

\begin{tabular}{|c|c|c|c|c|c|c|c|c|c|}
\hline & \multicolumn{3}{|c|}{ Leptin } & \multicolumn{3}{|c|}{ Adiponectin } & \multicolumn{3}{|c|}{ Leptin/adiponectin ratio } \\
\hline & $\beta$ & $95 \% \mathrm{Cl}$ & $p$ & $B$ & $95 \% \mathrm{Cl}$ & $p$ & $\beta$ & $95 \% \mathrm{Cl}$ & $p$ \\
\hline Model $1(n=147)$ & & & & & & & & & \\
\hline $\begin{array}{l}\text { HOMA-IR } \\
\text { Model } 2(n=135)\end{array}$ & 0.38 & $(0.23,0.53)$ & $<.001$ & -0.02 & $(-0.19,0.13)$ & 0.74 & 0.36 & $(0.21,0.51)$ & $<.001$ \\
\hline $\begin{array}{l}\text { HOMA-IR } \\
\text { Model } 3(n=135)\end{array}$ & 0.36 & $(0.21,0.51)$ & $<.001$ & -0.02 & $(-0.18,0.14)$ & 0.81 & 0.33 & $(0.19,0.48)$ & $<.001$ \\
\hline $\begin{array}{l}\text { HOMA-IR } \\
\text { Model } 4(n=127)\end{array}$ & 0.30 & $(0.15,0.45)$ & $<.001$ & -0.05 & $(-0.11,0.23)$ & 0.51 & 0.25 & $(0.10,0.40)$ & .001 \\
\hline
\end{tabular}

Model 1: unadjusted model; Model 2: adjusted for sex, age, and sexual maturation; Model 3: Model 2 with the addition of cardiorespiratory fitness; Model 4 Model 2 with the addition of muscular fitness; for HOMA-IR, cardiorespiratory fitness, muscular fitness, leptin, adiponectin, and leptin/adiponectin ratio standardised values (Z-scores) by age and sex were constructed.

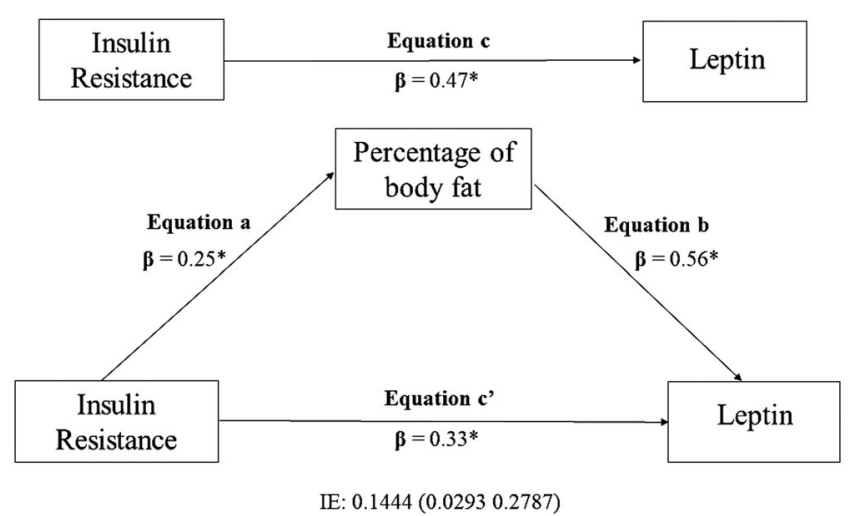

Figure 1. Mediation analysis of percentage of body fat in the association of insulin resistance with leptin (adjusted for sex, age, and sexual maturation). ${ }^{*} p<.05$.

and L/A ratio, while in the fourth equation $\left(c^{\prime}\right)$ when IR and \%BF were included simultaneously in the model, \%BF was associated with $\mathrm{L} / \mathrm{A}$ ratio $(p<.001)$. Besides, the relationship between IR and leptin was attenuated when \%BF was included in the model, indicating that \%BF is a mediator of this relationship (indirect effect $=0.1444$; IC: $0.0293 / 0.2787$ ), explaining $54 \%$ of this association. Likewise, the relationship between $\mathrm{IR}$ and $\mathrm{L} / \mathrm{A}$ ratio was attenuated when $\% \mathrm{BF}$ was included in the model, indicating that \%BF is a mediator of this relationship (indirect effect $=0.1002$; IC: $0.0219 / 0.2133$ ), explaining $57 \%$ of this association. Given the fact that adiponectin was not associated with $I R$, mediation analysis was not applied.

\section{Discussion}

The main findings of this study showed that IR was positively associated with leptin and L/A ratio after adjustment for variables of interest such as age, sex, sexual maturation, CRF, and MF. Moreover, the mediation analysis showed that the relationship of IR with leptin and IR with L/A ratio, are mediated for $\% B F$, explaining $54 \%$ and $57 \%$ of these associations, respectively.

Since adipose tissue secretes several adipokines with both positive and negative effects on insulin sensitivity and metabolism, adipokine signalling has emerged as a potential area for identifying and developing new therapies (Esser et al. 2014; Ghadge et al. 2018). To the best of our knowledge, this is the first study to report the mediation effect of

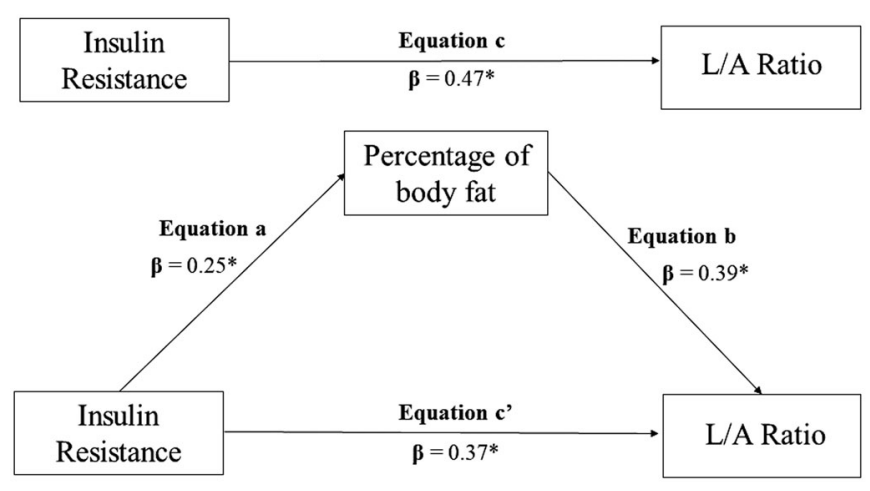

IE: $0.1002(0.02190 .2133)$

Figure 2. Mediation analysis of percentage of body fat in the association of insulin resistance with L/A ratio (adjusted for sex, age, and sexual maturation). ${ }^{*} p<.05$.

$\% \mathrm{BF}$ in the association of IR with leptin and L/A ratio in early ages. Our findings underscore the potential effect of adipocytokines levels on IR as well the key role of adiposity on this association. These results have public health and clinical implications since adiposity has been widely associated with several cardiometabolic diseases from childhood.

It is currently well accepted that obesity promotes a state of chronic low-grade inflammation, with both being strongly associated with IR (Al-Daghri et al. 2014). Although some studies have reported that plasma leptin is associated with IR independently of body fatness (Huang et al. 2004), we found that adiposity explains $54 \%$ of the association between IR and leptin, which agrees with other studies (Ropelle et al. 2010; Falcão-Pires et al. 2012). It is also important to take into consideration that age, body mass index, sex, and pubertal stage are the most important variables influencing serum leptin concentration (Mantovani et al. 2016; Zhu et al. 2016). Some studies have shown a positive association between IR and leptin in children and adolescents, even after controlling for potential confounding factors (Huang et al. 2004; Antunes et al. 2009; AgostinisSobrinho, Lacerda, et al. 2017), however, none of the abovementioned studies have adjusted their analysis for fitness. Thus, we highlight that leptin and L/A ratio are associated with IR, even after adjustments for age, sex, sexual maturation, CRF, and MF. Indeed, recently, some studies have reported that MF and CRF may play a key role in levels of IR from childhood to adulthood (Grøntved et al. 2013; Fraser 
et al. 2018). Therefore, the findings of the present study indicate that intervention studies should be focussed on maintaining physical fitness, as well as a healthy weight, considering its additive health benefits concerning IR and adipocytokines.

In addition, several studies have also shown that L/A ratio is a potential parameter to assess IR, although most of the knowledge on this topic comes from adolescents and adults (Finucane et al. 2009; López-Jaramillo et al. 2014; AgostinisSobrinho, Lacerda, et al. 2017). In our study, we found that that adiposity explains $57 \%$ of the association between IR and L/A ratio. Thus, given the rising prevalence of cardiometabolic dysfunctions in early ages and the linkage of this condition to inflammation, our study adds new insights showing this strong association in children of 6-11 years old. Therefore, it seems that the interaction between both adipokines (leptin and adiponectin), may have a strong association with cardiometabolic risk factors (López-Jaramillo et al. 2014; Agostinis-Sobrinho, Lacerda, et al. 2017).

Although leptin and L/A ratio are considered good markers of IR (López-Jaramillo et al. 2014), its measures are expensive and not easily accessible for the general population. Thus, our mediation analysis reinforces the relevance of adiposity as an important indicator of IR and diabetes risks. We also highlight that some measures of adiposity are considered simple, non-invasive, and low-cost methods that can be used to classify children, adolescents, and adults at risk of developing metabolic disorders, including IR and diabetes (Aristizabal et al. 2015; González-Jiménez et al. 2016).

Regarding adiponectin, we did not find a significant association with IR, as previously found (Aguilar et al. 2013). This result could be due to the age range considered in the present study, since children may not present high levels of adiponectin, also most studies are developed with adolescents and adults (Kajikawa et al. 2011; Aguilar et al. 2013). On the other hand, studies with children and adolescents indicated an inverse association between adiponectin and HOMA-IR (Panagopoulou et al. 2008; Aguilar et al. 2013). However, all these results should be interpreted with caution, considering that some evidence has pointed to a paradoxical role of adiponectin levels on health status (Esmaili et al. 2014). Initially, low levels of adiponectin were considered an independent risk factor for cardiovascular disease (Ai et al. 2011), but, recently and curiously, some evidence has suggested that high serum adiponectin concentration is associated with an increased risk of cardiovascular disease in the elderly (Choi et al. 2015).

Strengths of this study include new information regarding the associations between IR, adiposity, leptin, adiponectin, and L/A ratio in children. Indeed, most studies regarding this topic were developed with adolescents or adults. Further, we used the gold standard to measure body fat. In our study, we considered important confounding variables such as CRF and MF. Finally, although a growing number of studies have examined the association between IR with L/A ratio and mainly leptin, none of them have evaluated the mediation role of adiposity in this relationship.
Some limitations of our study should also be pointed out. Firstly, the cross-sectional nature of the study did not allow for causal inferences. Secondly, we did not include any measure of diet, which may influence the analysed variables. Thirdly, a single fasting baseline measurement of adipocytokines was used. Finally, the HOMA model is not the gold standard for assessing IR, although it provides good diagnosis value compared to the gold standard clamp techniques in validation studies of adolescents.

In conclusion, leptin and L/A ratio are positively associated with IR after adjustments for age, sex, sexual maturation, CRF, and MF. In addition, \%BF is a mediator on the associations between IR and leptin as well IR and L/A ratio.

\section{Disclosure statement}

No potential conflict of interest was reported by the author(s).

\section{Funding}

This work was supported by the National Council for Scientific and Technological Development (CNPQ) [ID: 477893/2013-9], Coordination for the Improvement of Higher Education Personnel (CAPES) and Foundation for Science and Technology (FCT), Portugal: [SFRH/BSAB/ 142983/2018 and UID/DTP/00617/2019].

\section{ORCID}

Caroline Brand (D) http://orcid.org/0000-0002-5624-3592

Adroaldo Cezar Araujo Gaya (D) http://orcid.org/0000-0002-5941-5089

Arieli Fernandes Dias (D) https://orcid.org/0000-0001-6648-8799

Cesar Agostinis-Sobrinho (iD http://orcid.org/0000-0001-9104-9042

Juliano Boufleur Farinha (D) http://orcid.org/0000-0003-4589-256X

Francesco Pinto Boeno iD https://orcid.org/0000-0001-7729-7015

Jorge Mota (D) http://orcid.org/0000-0001-7571-9181

Alvaro Reischak de Oliveira (ID http://orcid.org/0000-0003-4590-2991

Anelise Reis Gaya (iD) http://orcid.org/0000-0002-8335-6947

\section{References}

Agostinis-Sobrinho C, Moreira C, Abreu S, Lopes L, Oliveira-Santos J, Steene-Johannessen J, Mota J, et al. 2017. Serum adiponectin levels and cardiorespiratory fitness in nonoverweight and overweight Portuguese adolescents: the LabMed Physical Activity Study. Pediatr Exerc Sci. 29(2):237-244.

Agostinis-Sobrinho C, Santos R, Moreira C, Abreu S, Lopes L, OliveiraSantos J, Rosário R, et al. 2016. Association between serum adiponectin levels and muscular fitness in Portuguese adolescents: LabMed Physical Activity Study. Nutr Metab Cardiovasc Dis. 26(6):517-524.

Agostinis-Sobrinho CA, Lacerda E, Moreira C, Abreu S, Lopes L, OliveiraSantos J, Skuryydas A, et al. 2017. Association between leptin, adiponectin, and leptin/adiponectin ratio with clustered metabolic risk factors in Portuguese adolescents: the LabMed. Ann Nutr Metab. 70(4): 321-328.

Agostinis-Sobrinho CA, Ramírez-Vélez R, García-Hermoso A, Moreira C, Lopes L, Oliveira-Santos J, Abreu S, et al. 2018. Low-grade inflammation and muscular fitness on insulin resistance in adolescents: results from LabMed Physical Activity Study. Pediatr Diabetes. 19(3):429-435.

Aguilar MJ, González-Jiménez E, Antelo A, Perona JS. 2013. Insulin resistance and inflammation markers: correlations in obese adolescents. J Clin Nurs. 22(13-14):2002-2010.

Ai M, Otokozawa S, Asztalos BF, White CC, Cupples LA, Nakajima K, Lamon-Fava S, et al. 2011. Adiponectin: an independent risk factor for 
coronary heart disease in men in the Framingham offspring study. Atherosclerosis. 217(2):543-548.

Al-Daghri NM, Al-Attas OS, Alokail M, Alkharfy K, Wani K, Amer OE, UI Haq S, et al. 2014. Does visceral adiposity index signify early metabolic risk in children and adolescents?: association with insulin resistance, adipokines, and subclinical inflammation. Pediatr Res. 75(3): 459-463.

Allison MB, Myers MG. 2014. Connecting leptin signaling to biological function. J Endocrinol. 223(1):T25-T35.

Antunes H, Santos C, Carvalho S. 2009. Serum leptin levels in overweight children and adolescents. Br J Nutr. 101(8):1262-1266.

Aristizabal JC, Barona J, Hoyos M, Ruiz M, Marín C. 2015. Association between anthropometric indices and cardiometabolic risk factors in pre-school children. BMC Pediatr. 15:170.

Aycan Z, Berberoğlu M, Ocal G, Evliyaoglu O, Adiyaman P, Deda G, Caksen $\mathrm{H}$, et al. 2005. Relationship between plasma leptin, insulin and tumor necrosis factor alpha in obese children. J Pediatr Endocrinol Metab. 18(3):275-284.

Baron RM, Kenny DA. 1986. The moderator-mediator variable distinction in social psychological research: conceptual, strategic, and statistical considerations. J Pers Soc Psychol. 51(6):1173-1118.

Bergmann GG, Bergmann MLA, Castro AAMC, Lorenzi TD, Pinheiro ES, Moreira RB, Marques AC. 2014. Use of the 6-minute walk/run test to predict peak oxygen uptake in adolescents. Rev Bras Ativ Fis Saúde. 19(1):64-73.

Choi SH, Ku EJ, Hong ES, Lim S, Kim KW, Moon JH, Kim KM, et al. 2015. High serum adiponectin concentration and low body mass index are significantly associated with increased all-cause and cardiovascular mortality in an elderly cohort, "adiponectin paradox": the Korean Longitudinal Study on Health and Aging (KLoSHA). Int J Cardiol. 183: 91-97.

Esmaili S, Xu A, George J. 2014. The multifaceted and controversial immunometabolic actions of adiponectin. Trends Endocrinol Metab. 25(9):444-451.

Esser N, Legrand-Poels S, Piette J, Scheen AJ, Paquot N. 2014 Inflammation as a link between obesity, metabolic syndrome and type 2 diabetes. Diabetes Res Clin Pract. 105(2):141-150.

Falcão-Pires I, Castro-Chaves P, Miranda-Silva D, Lourenço AP, LeiteMoreira AF. 2012. Physiological, pathological and potential therapeutic roles of adipokines. Drug Discov Today. 17(15-16):880-889.

Finucane FM, Luan J, Wareham NJ, Sharp SJ, O'Rahilly S, Balkau B, Flyvbjerg A, et al. 2009. Correlation of the leptin: adiponectin ratio with measures of insulin resistance in non-diabetic individuals. Diabetologia. 52(11):2345-2349.

Fraser BJ, Blizzard L, Schmidt MD, Juonala M, Dwyer T, Venn AJ, Magnussen CG. 2018. Childhood cardiorespiratory fitness, muscular fitness and adult measures of glucose homeostasis. J Sci Med Sport. 21(9):935-940.

Friend A, Craig L, Turner S. 2013. The prevalence of metabolic syndrome in children: a systematic review of the literature. Metab Syndr Relat Disord. 11(2):71-80.

Gaya A, Gaya A. 2016. Manual de testes e avaliação do Projeto Esporte Brasil - PROESP-Br. [accessed 2019 July 10]. https://www.ufrgs.br/proesp/arquivos/manual-proesp-br-2016.pdf.

Ghadge AA, Khaire AA, Kuvalekar AA. 2018. Adiponectin: a potential therapeutic target for metabolic syndrome. Cytokine Growth Factor Rev. 39:151-158.

González-Jiménez E, Schmidt-RioValle J, Montero-Alonso MA, Padez C García-García CJ, Perona JS. 2016. Influence of biochemical and anthropometric factors on the presence of insulin resistance in adolescents. Bio Res Nurs. 18(5):541-548.
Grøntved A, Ried-Larsen M, Ekelund U, Froberg K, Brage S, Andersen LB. 2013. Independent and combined association of muscle strength and cardiorespiratory fitness in youth with insulin resistance and $\beta$-cell function in young adulthood: the European Youth Heart Study. Diabetes Care. 36(9):2575-2581.

Huang KC, Lin RCY, Kormas N, Lee LT, Chen CY, Gill TP, Caterson ID. 2004. Plasma leptin is associated with insulin resistance independent of age, body mass index, fat mass, lipids, and pubertal development in nondiabetic adolescents. Int J Obes. 28(4):470-475.

Kajikawa Y, Ikeda M, Takemoto S, Tomoda J, Ohmaru N, Kusachi S. 2011. Association of circulating levels of leptin and adiponectin with metabolic syndrome and coronary heart disease in patients with various coronary risk factors. Int Heart J. 52(1):17-22.

López-Jaramillo P, Gómez-Arbeláez D, López-López J, López-López C, Martínez-Ortega J, Gómez-Rodríguez A, Triana-Cubillos S. 2014. The role of leptin/adiponectin ratio in metabolic syndrome and diabetes. Horm Mol Biol Clin Invest. 18(1):37-45.

Mantovani RM, Rocha NP, Magalhães DM, Barbosa IG, Teixeira AL, Silva AC. 2016. Early changes in adipokines from overweight to obesity in children and adolescents. J Pediatr. 92(6):624-630.

Matthews DR, Hosker JP, Rudenski S, Naylor B, Treacher DF, Turner RC. 1985. Homeostasis model assessment: insulin resistance and beta-cell function from fasting plasma glucose and insulin concentrations in man. Diabetologia. 28(7):412-419.

Medeiros CCM, Ramos AT, Cardoso MAA, França ISX, Cardoso AS, Gonzaga NC, Carvalho DF. 2011. Insulin resistance and its association with metabolic syndrome components. Arq Bras Cardiol. 97(5): 380-389.

Mirwald RL, Baxter-Jones ADG, Bailey D, Beunen GP. 2002. An assessment of maturity from anthropometric measurements. Med Sci Sports Exerc. 34(4):689-694

Panagopoulou P, Galli-Tsinopoulou A, Fleva A, Pavlitou-Tsiontsi E, Vavatsi-Christaki N, Nousia-Arvanitakis S. 2008. Adiponectin and insulin resistance in childhood obesity. J Pediatr Gastroenterol Nutr. 47(3): 356-362.

Pittas AG, Joseph NA, Greenberg AS. 2004. Adipocytokines and insulin resistance. J Clin Endocrinol Metab. 89(2):447-452.

Preacher KJ, Hayes AF. 2008. Asymptotic and resampling strategies for assessing and comparing indirect effects in multiple mediator models. Behav Res Methods. 40(3):879-891.

Romualdo M, Nóbrega FJ, Escrivão M. 2014. Insulin resistance in obese children and adolescents. J Pediatr. 90(6):600-607.

Ropelle ER, Flores MB, Cintra DE, Rocha GZ, Pauli JR, Morari J, de Souza CT, et al. 2010. IL-6 and IL-10 anti-inflammatory activity links exercise to hypothalamic insulin and leptin sensitivity through IKK $\beta$ and ER stress inhibition. PLoS Biol. 8(8):31-32.

Ruiz JR, Castro-Piñero J, Artero EG, Ortega FB, Sjöström M, Suni J, Castillo MJ. 2009. Predictive validity of health-related fitness in youth: a systematic review. Br J Sports Med. 43(12):909-923.

Skoczen S, Wojcik M, Fijorek K, Siedlar M, Starzyk JB. 2015. Expression of the central obesity and type 2 diabetes mellitus genes is associated with insulin resistance in young obese children. Exp Clin Endocrinol Diabetes. 123(4):252-259.

Van Greevenbroek MMJ, Schalkwijk CG, Stehouwer CD. 2013. Obesityassociated low-grade inflammation in type 2 diabetes mellitus: causes and consequences. Neth J Med. 71(4):174-187.

Yadav A, Kataria MA, Saini V, Yadav A. 2013. Role of leptin and adiponectin in insulin resistance. Clin Chim Acta. 417:80-84.

Zhu HJ, Li SJ, Pan H, Li N, Zhang DX, Wang LJ, Yang HB, et al. 2016. The changes of serum leptin and kisspeptin levels in Chinese children and adolescents in different pubertal stages. Int J Endocrinol. 2016:1-11. 